\title{
Gambling: spreading among students in Palermo
}

\author{
Fabio Venturella, ${ }^{1}$ Anastasia Valentina Liga, ${ }^{1}$ Marco Giammanco, ${ }^{2}$ Giulia Cancellieri ${ }^{1}$ \\ ${ }^{1}$ Biological, Chemical and Pharmaceutical Science and Technologies Department; ${ }^{2}$ Department of Experimental \\ Biomedicine and Clinical Neurosciences, University of Palermo, Italy
}

\begin{abstract}
Adolescents represent a particularly high-risk group and they are also vulnerable to the development of gambling related problems. Thanks to technological advances in gaming industry (slot machines, video lottery terminals, casino-types games) new form of gambling are continuously appearing. With the purpose of having an idea about the spreading of gambling among the students of Palermo, a survey has been conducted through administration of questionnaires during the period from January to May 2017: this study involved 1622 students ( 686 boys and 936 girls) between the age of 14 and 19. In this survey it has been demonstrated that only $15 \%$ of students have never played; $36 \%$ declare they have played cards with money at least once in their life and $19 \%$ of them play lotteries and scratchers; some others have played sport betting (14\%), bingo (7\%), slot machines $(5 \%)$, horse betting $(4 \%)$. The money spent on a single day is between 1 and 10 euros (584 students); 530 teenagers spend 1 euro or less; 132 between $1 \mathrm{o}$ and 100 euros; 16 students more than 100 euros/die. Moreover, most alarming is evidence indicating that there is a considerable number of students who have gambling players parents (father $18,65 \%$; mother $16,4 \%$; both of them $4,52 \%$ ): this is considered an important vulnerability factor. The analysis of the picked data suggests that there is a widespread diffusion of gambling among the adolescent population. So, to conclude, the present research points out the need
\end{abstract}

Correspondence: Giulia Cancellieri, Biological, Chemical and Pharmaceutical Science and Technologies Department University of Palermo, Via Archirafi 20, 90123 Palermo, Italy.

Tel.: +39.3298497784.

E-mail: giulia.cancellieri@hotmail.it

Key words: Gambling; New addiction; Adolescents.

Conference presentation: part of this paper was presented at the National SIBS Congress, Trapani, Italy, 27 October 2017.

Received for publication: 11 April 2018.

Revision received: 16 July 2018.

Accepted for publication: 20 July 2018.

CCopyright F. Venturella et al., 2018

Licensee PAGEPress, Italy

Journal of Biological Research 2018; $91: 7498$

doi:10.4081/jbr.2018.7498

This article is distributed under the terms of the Creative Commons Attribution Noncommercial License (by-nc 4.0) which permits any noncommercial use, distribution, and reproduction in any medium, provided the original author(s) and source are credited. to complete immediate interventions on both levels of information and prevention.

\section{Introduction}

Gambling is classified as New Addiction, which is a pathological addiction without chemical substance. ${ }^{1}$ It comes from different exogenous incentives and it is able to produce in vulnerable individuals not only repeated and atypical compulsive behavioral responses but also neuroplastic effects, tolerance and craving. In particular, in the gambler we notice, on the one hand, a reduction in the voluntary control managed by the Controller (mainly comprising the ventromedial and orbitofrontal portion of the prefrontal cortex and the 5-HT system), on the other an increase in impulses resulting from emotional Drive (comprising Amygdala, Insula and the NA system). Recent studies have shown that, during adolescence, it is customary the occurrence of an imbalance between Drive and Controller which causes low behavioral control capacity associated with high rewarding ability that can lead to an increase in the risk of dangerous behavior to health and integrity of the adolescent. ${ }^{2}$

To confirm that, it has been shown that, in adolescents, the prefrontal regions, responsible for decision making and voluntary behavioral control, develop late compared to the limbic regions, responsible instead for emotional impulses and craving towards rewarding incentives, such as gambling. ${ }^{3}$ Our research was aimed at evaluating the prevalence of behaviors attributable to gambling among adolescents by the administration of a questionnaire to students from the main high schools of Palermo.

\section{Materials and Methods}

We conducted a survey by administering a questionnaire, composed by 12 items (based and reworked on South Oaks Gambling Screen, created by Leieur and Blume, 1987) ${ }^{4}$ during the period from January to May 2017: we evaluated 1622 teenagers (936 girls and 686 boys) between the ages of 14 and 19, living in Palermo (Sicily, Italy). The test was administered individually and anonymously, during school time, in the main schools of Palermo, such as State Magistral Institute "C. Finocchiaro Aprile", Institute of Higher Education "Francesco Ferrara", IPSSAR "Francesco Paolo Cascino", Professional and Commercial Institute "Luigi Einaudi", State High School of Art "Catalano", Classical High School "Vittorio Emanuele II", State Magistral Institute "De Cosmi". We extrapolated data by using a worksheet on Microsoft Excel and then we created the graphs based on the results obtained (Microsoft Excel). This survey is included in the Prevention and 
Information about New and Rape Drugs, Addiction e Amateur Doping project, sponsored by University of Palermo and Health department of the Sicilian Region.

\section{Results and Discussion}

By analyzing the answers obtained from the questionnaire we got the graph illustrated in Figure 1: it indicates which are the most common games among adolescents.

As can be seen from this graph, only $15 \%$ of students affirmed they have never played money during their lives; $36 \%$ have played cards with cash at least once; $19 \%$ have played lotto, lotteries, and scratch cards; $14 \%$ sports betting. Horse racing betting (4\%) is the least popular game among teenagers, along with slot machines and video poker $(5 \%)$ and bingo $(7 \%)$.

We also evaluated the frequency with which such games are played: in all the games analyzed the frequency is "less than once a week"; the answer "more than once a week", however, is significant for sports bets, to play cards with money, lot/lotteries/scratch cards (Figure 2).

Then we asked them to indicate the largest amount of money ever bet in a single day: As shown in the graph illustrated in Figure 3 this amount is between 1 and 10 euros (584 students); it follows the range estimated between of 1 euro or less (530 students). 132 students out of 1622 , instead, claim to have bet between 10 and 100 euros, while 16 students even more than 100 euros/day.

Finally we looked into the existence of sentinel symptoms among adolescents, which are incorrect behavior that increase the risk of developing a pathological condition related to gambling. Examples of sentinel symptoms are: restlessness, guilty conscience, loneliness, taking time away from school, lies, mainly to family members, small crimes and failure to repay borrowed money. ${ }^{5}$ The data obtained suggest that an average of 200 subjects out of 1622 presents compulsive gambling behaviors and it is on them that it would be better to act with prevention and information works.

\section{Conclusions}

The analysis we carried out confirms the high risk, during adolescence, of developing a pathological condition of gambling: in fact, a decent portion of the population analyzed presents some gambling behaviors that need to be corrected. In order to limit as much as possible this phenomenon it was decided to act socioenvironmental measures without which all other preventive measures could be useless: in particular, the target is to regulate advertising campaigns and online gaming. This is because advertisements on gambling are able to strongly influence adolescents. ${ }^{6}$ For this reason, it was thought to: i) to declare in all advertisements that gambling can create pathological dependence and generate side effects on the mental, physical and social health conditions; ii) to discourage the use of celebrity to advertise gambling, since they could push to emulation. Instead, with regard to the adolescent - online gaming correlation it was thought to: i) to encourage parents to monitor their children while surfing the Internet; ii) To maintain control over authorizations for online gambling sites in the hands of the state; iii) to forbid online gaming companies to sending spam or making pop-up appear on sites dedicated to young people.

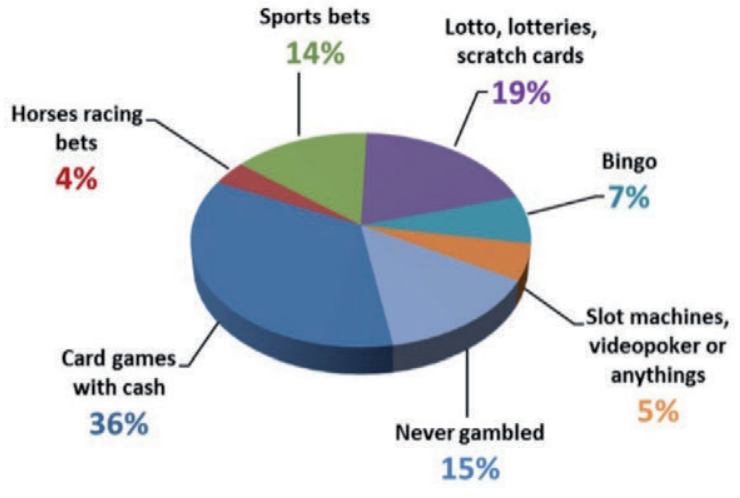

Figure 1. Most common games among adolescents in Palermo.

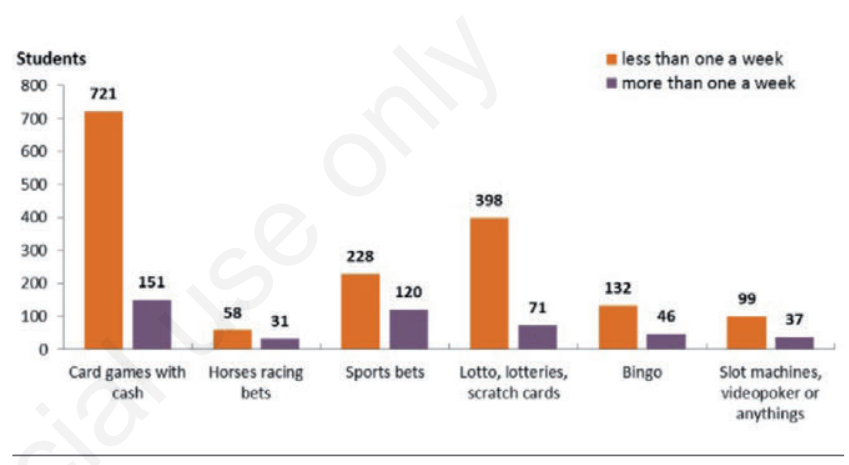

Figure 2. Analysis of the frequency of gambling among adolescents in Palermo.

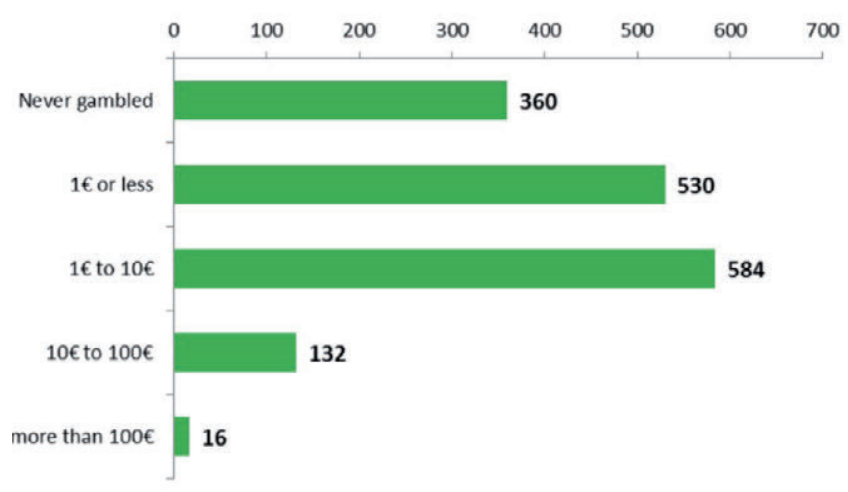

Figure 3. The largest amount of money ever bet in a single day.

\section{References}

1. American Psychiatric Association. Diagnostic and statistical manual of mental disorders. 5th ed. Arlington, VA: American Psychiatric Publishing; 2013.

2. Serpelloni G, Rimondo C. Gioco d'azzardo problematico e patologico: inquadramento generale, meccanismi fisiopatologici, 
vulnerabilità, evidenze scientifiche per la prevenzione, cura e riabilitazione. Ital J Addict 2012;2:7-44.

3. Joutsa J, Saunavaara J, Parkkola R, et al. Extensive abnormaility of brain white matter integrity in pathological gambling. Psychiatry Res: Neuroimag 2011;194:340-6.

4. Lesieur HR, Blume SB. The South Oaks Gambling Screen (SOGS): a new instrument for the identification of pathological gamblers. Am J Psychiatry 1987;144:1184-8.
5. Conversano C, Marazziti D, Carmassi C. Pathological gambling: a systematic review of biochemical, neuroimaging, and neuropsychological findings. Harv Rev Psychiatry 2012;20:130-48.

6. Potenza MN, Wareham JD, Steinberg MA, et al. Correlates of at-risk/problem internet gambling in adolescents. J Am Acad Child Adolesc Psychiatry 2011;50:150-9. 